\title{
O contraditório direito à saúde de pessoas em privação de liberdade: o caso de uma unidade prisional de Minas Gerais
}

\section{The contradictory right to health of people deprived of liberty: the case of a prison in Minas Gerais, Brazil}

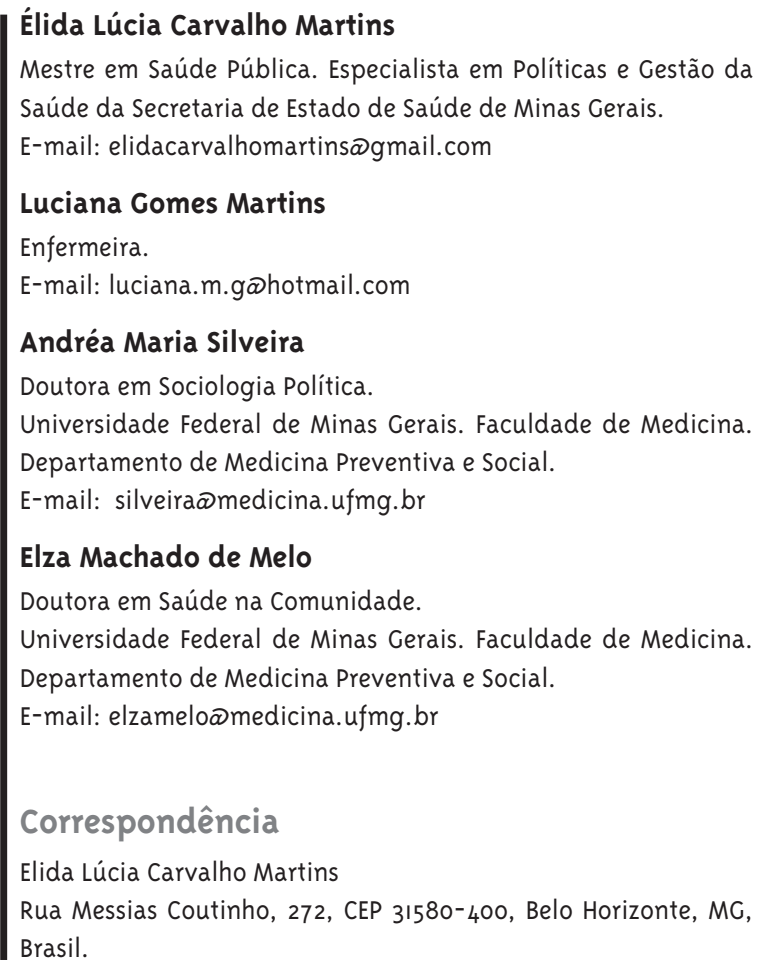

\section{Correspondência}

Elida Lúcia Carvalho Martins

Rua Messias Coutinho, 272, CEP 31580-400, Belo Horizonte, MG, Brasil.

\section{Resumo}

Este trabalho tem por objetivo analisar a efetivação do direito à saúde das pessoas em privação de liberdade, por meio de grupos focais realizados com três grupos focais com sujeitos envolvidos no contexto carcerário: pessoas presas, agentes penitenciários e profissionais de saúde de uma unidade prisional masculina em Ribeirão das Neves (MG). As discussões foram gravadas, transcritas e submetidas a análise de discurso. 0 direito à saúde, compreendido como acesso integral a serviços de saúde de qualidade, é questionado enquanto fenômeno real, uma vez que, estando os serviços públicos sucateados, esse acesso está restrito a quem pode pagar. 0 descaso do Estado em relação ao direito à saúde das pessoas presas é justificado pela função disciplinar da prisão. As precárias condições de trabalho e o julgamento moral sobre a conduta do preso indicam uma recusa em reconhecer a legitimidade de seu direito à saúde. Ainda que as leis brasileiras afirmem saúde como direito de todos e dever do Estado, constata-se a não realização desse direito tanto para as pessoas presas como para os profissionais que atuam no presídio. Palavras-chave: Direito à Saúde; Prisões; Violência; Condições de Trabalho. 


\section{Abstract}

This paper aims to analyze the realization of the right to health of people deprived of liberty, by means of focus groups conducted with three subjects involved in the prison context: imprisoned people, prison officers, and health professionals in a male prison in Ribeirão das Neves, Minas Gerais, Brazil. The discussions were recorded, transcribed, and underwent discourse analysis. The right to health, understood as full access to good-quality health services, is put into question as an actual phenomenon, since, considering that public services are scrapped, this access is restricted to those who can pay for it. State neglect with regard to the right to health of imprisoned people is justified by the disciplinary role played by prison. Poor working conditions and moral judgment on the prisoner's behavior indicate a refusal to recognize the legitimacy of his right to health. Although the Brazilian laws claim that health is a right of all and a duty of the State, we find out the lack of realization of this right both for imprisoned people and for the professionals working in the prison.

Keywords: Right to Health; Prisons; Violence; Working Conditions.

\section{Introdução}

O aumento da população carcerária é uma realidade nos países industrializados ou em processo de industrialização (Walmsley, 2009). Em 2008, a população mundial foi estimada pela Organização das Nações Unidas (ONU) em 6,75 bilhões de pessoas, das quais 9,8 milhões encontram-se presas, significando uma taxa de encarceramento mundial de 145 por 100.000 habitantes. O Brasil possui a maior população carcerária da América Latina (Walmsley, 2009). Em dezembro de 2012, eram 548.003 presos em 1.881 estabelecimentos penais (incluindo os que estão sob custódia da polícia civil) ${ }^{1}$, com uma taxa de encarceramento de 287,31 por 100 .ooo habitantes (Brasil, 2012). Nos últimos cinco anos, em Minas Gerais, houve um aumento de $89,8 \%$ da população carcerária (Conselho Nacional de Justiça, 2010) e, em dezembro de 2012, a taxa de encarceramento registrada no Estado foi de 263,32/100.ooo habitantes (Brasil, 2010a).

As precárias condições do sistema penitenciário brasileiro são bem conhecidas: superlotação, condições sanitárias rudimentares, alimentação insuficiente, ausência de assistência médica, jurídica, educacional e profissional. Tem-se, ainda, constante violência entre os presos e entre esses e o Estado, representado por policiais e agentes penitenciários (Brasil, 2000, Mesquita Neto e Alves, 2007; CEJIL, 2007; Diuana e col., 2008). Tudo isso, somado ao uso de drogas e ao sedentarismo, torna a prisão um local de grande risco para a saúde (Assis, 2007).

A despeito das penas de caráter cruel terem sido vedadas pela Constituição Federal em vigência (Brasil, 1988) e a pena de prisão se restringir à perda da liberdade, não de outros direitos fundamentais (Brasil, 1988), há no sistema prisional riscos ligados à integridade física, à falta de infraestrutura e às doenças infectocontagiosas, além de uma desvalorização do preso e de suas queixas apresentadas inicialmente aos agentes penitenciários. Estes fazem uma avaliação informal do caso e decidem, com

1 A Polícia Judiciária é responsável por realizar investigações, colher provas por meio do inquérito policial e entregar ao Ministério Público, que procederá a acusação do acusado. A Polícia Judiciária nos âmbitos estaduais e municipais é exercida pela Polícia Civil, no âmbito federal pela Polícia Federal. A custódia dos presos é legalmente exercida pelos agentes penitenciários, quando estão em prisões. Porém, foi atribuído, sem qualquer amparo legal (Borges Netto e Silva, 2007), à Polícia Judiciária o poder de custódia dos presos que estão em prisão preventiva ou até mesmo aqueles com sentença transitado em julgado. Por isso, as delegacias da Polícia Judiciária são usadas também como carceragem. Tal custódia é exercida pelo controle dos carcereiros policiais, que são funcionários da Polícia Judiciária. 
base em critérios pessoais, o encaminhamento ou não do preso ao serviço médico, resultando em um controle do acesso aos serviços de saúde. Segundo Diuana e colaboradores (2008), a produção de ações de saúde hierarquizadas e focadas na doença indica a resistência por parte dos agentes penitenciários, da administração penitenciária e da sociedade civil em considerar a saúde como um direito do preso.

\section{Marco legal}

O direito à saúde da população em privação de liberdade foi normatizado na legislação brasileira pela Lei de Execução Penal (LEP) n. 7.210, de 11 de julho de 1984 (Brasil, 1984), que dispõe sobre as condições de cumprimento das sentenças criminais e sobre as condições para proporcionar a integração social do condenado e do internado. Segundo a LEP (Brasil, 1984), a assistência à saúde é um direito das pessoas em privação de liberdade, tem caráter curativo e preventivo e compreende o atendimento médico, farmacêutico e odontológico. Além disso, a norma legal determina que o acesso a serviços de saúde de unidade prisional equipada ocorrerá mediante autorização da direção do estabelecimento (Brasil, 1984).

Nesse cenário, não é mero acaso a institucionalização do Plano Nacional de Saúde no Sistema Penitenciário (PNSSP) pela Portaria Interministerial n. 1.777, dos ministérios da Saúde e da Justiça, de 9 de setembro de 2003, na qual se prevê a necessidade de organização de ações e serviços de saúde no sistema penitenciário orientados pelos princípios e diretrizes do Sistema Único de Saúde (SUS) (Brasil, 2003). O PNSSP é guiado pela lógica da atenção básica e define a corresponsabilidade das três esferas de governo pela gestão das ações e dos serviços de saúde no sistema penitenciário (Brasil, 201ob).

O plano define como prioridades da política: reforma e equipagem das unidades prisionais; organização do sistema de informação de saúde; implantação de ações de promoção da saúde; implementação de medidas de proteção específicas para hepatites, tuberculose, hanseníase, diabetes, hipertensão, DST/aids e agravos psicossociais decorrentes do confinamento; distribuição de preservativos e insumos para a redução de danos associados ao uso de drogas; garantia de acesso aos demais níveis de atenção à saúde, por meio das referências, incluídas na Programação Pactuada Integrada (PPI) estadual.

0 presente trabalho propõe-se a compreender e discutir a efetivação do direito à saúde das pessoas em privação de liberdade como disposto nas legislações que o regulamentam.

\section{Percurso metodológico}

Trata-se de estudo qualitativo sobre o direito à saúde das pessoas em privação de liberdade, realizado no ano de 2011 em um presídio destinado à população carcerária masculina, situado no município de Ribeirão das Neves, MG.

Participaram do estudo: pessoas em privação de liberdade, agentes penitenciários e profissionais de saúde da unidade prisional. Aos grupos propusemos a discussão sobre o que era o direito à saúde, como ele se realizava na unidade prisional e quais os principais determinantes para se concretizar o direito à saúde na unidade. Todos os participantes da pesquisa assinaram o Termo de Consentimento Livre e Esclarecido. $\mathrm{O}$ trabalho foi aprovado pelo Comitê de Ética em Pesquisa da Universidade Federal de Minas Gerais (COEP/UFMG), n. CAAE - 0323.0.203.00o-11.

Os dados foram coletados por meio de grupos focais, realizados na própria unidade prisional. A escolha dessa técnica fundamentou-se na sua potencialidade de se explorar e aprofundar os conceitos, interesses, preocupações e percepções comuns e conflituosas que emergem da interação social (Gaskell, 2008): "O grupo focal é um ambiente mais natural e holístico em que os participantes levam em consideração os pontos de vistas dos outros na formulação de suas respostas e comentam suas próprias experiências e as dos outros" (p. 76). Além disso, esse tipo de procedimento metodológico, dada sua natureza interativa (Whestphal e col., 1996; Gatti, 2005; Gaskell, 2008), contribuiu para quebrar o constrangimento próprio do cenário de estudo e, ainda, propiciou um espaço não vigiado para a obtenção dos dados. A formação dos grupos foi feita a partir de um processo de negociação envolvendo a Secretaria de Estado de Defesa Social de Minas Gerais (SEDS/MG) e o diretor geral e os diretores de ressocialização e de segurança do presídio. Foram realizados três grupos focais, assim organizados: 


\section{Grupos focais com as pessoas em privação de liberdade - GFI}

Em virtude das dificuldades logísticas para se agrupar presos de diferentes pavilhões e de se fazer um convite aberto a todos os detentos, uma vez que o trânsito dos internos obedece a protocolos estabelecidos, foram incluídos na pesquisa os presos que estudam. Esse grupo é pré-formado, mas não selecionado, pela administração do presídio, uma vez que a inscrição na escola é realizada a pedido do detento. A pesquisa se limitou aos presos do ensino fundamental, único nível de escolarização para o qual existem turmas regulares. Foi permitida a entrada em apenas dois pavilhões do presídio, obedecendo às normas e à direção do estabelecimento, o que reduziu as possibilidades de seleção e amostra.

Os encontros foram realizados nas salas de aula, que se localizam dentro do pavilhão, sem a presença de agentes penitenciários, profissionais de saúde, professores ou qualquer outro funcionário do presídio. A utilização desse espaço contou com a autorização previa da SEDS/MG e da direção da escola do presídio. Foram formados dois grupos, um em cada pavilhão, um com oito participantes e outro com onze. A realização do grupo focal foi precedida de um encontro, no qual as pessoas em privação de liberdade foram convidadas a participar e os pesquisadores explicaram os objetivos do estudo e o método a ser utilizado.

Foram realizados quatro encontros, com duração média de uma hora, previamente acordados com os sujeitos, durante os quais foram realizadas dinâmicas e conversações entre os participantes com o objetivo de facilitar a interação entre os participantes e os moderadores. Para iniciar a discussão sobre direito à saúde foi exibido o filme "Um ato de coragem", de Nick Cassavetes.

\section{Grupo focal com agentes penitenciários - GF2}

O recrutamento de agentes penitenciários para a pesquisa não foi uma tarefa fácil, pelo fato de eles não poderem abandonar os postos de trabalho nem continuar no presídio após o término do plantão. Para contornar essa limitação, foram escolhidos os agentes de trânsito interno que têm a responsabilidade de fazer o deslocamento dos detentos entre a cela e as demais dependências da unidade, tarefa que poderia ser coberta por outros agentes penitenciários, caso necessário. No início houve certa resistência, mas ao final do primeiro encontro, com as explicações dadas, formou-se um grupo com seis agentes penitenciários.

Foram realizados quatro encontros, com duração média de uma hora cada, previamente acordados com os sujeitos, seguindo a mesma metodologia adotada para os grupos focais com as pessoas privadas de liberdade.

\section{Grupo focal com profissionais de saúde - GF3}

Os profissionais de saúde foram reunidos nas dependências do Núcleo de Atendimento à Saúde da unidade prisional para a explicação da pesquisa. Em virtude da rotina de trabalho, dividida em plantões, e da dificuldade de se interromper o atendimento aos presos, os grupos foram formados com os profissionais que estavam em escala conjunta de plantão, a cada quinze dias.

Apesar de a literatura recomendar o mínimo de seis participantes (Gatti, 2005), esse grupo foi realizado com cinco integrantes, para não se inviabilizar a pesquisa. Foram realizados dois encontros, com duração média de duas horas. Para o grupo dos profissionais de saúde não foi possível a realização da dinâmica e exibição do filme, uma vez que a cada encontro os atendimentos de saúde eram interrompidos, sendo necessário que o tempo concedido fosse usado apenas para a discussão.

Os grupos foram conduzidos por duas pesquisadoras: uma atuando como moderadora, outra como observadora. A moderadora teve papel de estimular a participação de todos - distribuir a fala para que ninguém a monopolizasse - e promover o debate pontuando os consensos e as divergências entre as falas e colocando em pauta questões suscitadas pela discussão. A observadora auxiliou anotando os comportamentos, expressões, falas e a dinâmica do grupo. Esses papéis foram desempenhados pela primeira e segunda autora deste artigo, respectivamente. Os encontros foram suficientes para obtenção de material necessário para compreensão e saturação das opiniões sobre o problema.

As discussões foram registradas por meio de um gravador digital e, posteriormente, transcritas. Após a transcrição, os discursos de cada grupo focal foram analisados por meio da análise de discurso (Gill, 
2008) e triangulados, com intuito de avaliar o objeto desta pesquisa à luz do encontro das percepções dos três atores inseridos na mesma realidade, superando a dicotomia entre o subjetivo e o objetivo (Minayo, 2010). Portanto, os resultados apresentados são as percepções comuns aos três grupos focais.

\section{Resultados e discussão}

\section{A saúde e o direito à saúde}

As falas dos profissionais de saúde do presídio mostram sintonia com o princípio da integralidade (Buss, 2000; Mattos, 2006; Paim, 2008):

Segundo a Organização Mundial, saúde é o bem-estar físico, mental, social e não só a ausência da doença, né? Então, é tudo engloba o ser humano, completo (GF3)

O mesmo ocorre com as pessoas presas, para as quais a saúde é liberdade: [...] liberdade pra mim é saúde [...]; respeito pelo outro: [...] começa pelo respeito ao próximo, porque se você falar da saúde, questão de mal tratar, não ter respeito com você, não te ver como um ser humano [...]; trabalho: [...] se eu 'tivé trabaiando' lá honestamente, eu 'vô tá' de bem com a vida [...]; e local onde se vive: [...] uma casa, piscina, uma árvore, um canteirozinho de rosas, céu $e$ as andorinhas voando [...](GF1).

Para os agentes penitenciários, é tudo isso e mais as condições de trabalho:

Você não sabe onde você vai apoiar, onde você vai segurar, aí você se abala. Você não tem suporte suficiente pra tá fazendo qualquer coisa, abala mentalmente [...] todos os acessos aqui 'é' complicado, tanto pra gente quanto pro preso. Você não sabe como fazer nada, você tem dificuldade pra fazer qualquer outra coisa, você não tá seguro de nada que vocêfaz. E acaba abalando mentalmente, fisicamente, você fica nervoso, mas tem que ficar calado em diversas situações. Muitas vezes, não pode dar sua opinião sobre o que 'tá' certo e o que 'tá' errado. $\varepsilon$ isso vai te abalando, vai desmoronando aos poucos. Até que você chega e basicamente não sabe quem évocêmais [...] Aívocêvvai só abaixando, abaixando, abaixando e fala: 'acabou'. (GF2)

Os entrevistados compreendem a saúde, também, como um direito e assim o definem:
Direito àsaúde équando a pessoa 'tá' passando mal e precisa ser 'atendido'. A pessoa 'tá precisando, 'tá' passando mal, precisa ser 'atendido'. Se 'ocê' precisa de medicamento, de operação, de atendimento médico, do que precisar, entendeu? (GF1)

Conceito próximo ao formulado por Pinheiro e colaboradores (2010):

[...] o direito à saúde é ter acesso universal aos cuidados em saúde, com recursos necessários para provê-los, sendo oferecidos por serviços de qualidade, nos quais as práticas culturais são consideradas, e a educação e informação sejam meios de sua produção e reprodução social (p. 17).

Essa compreensão é, de acordo com Bodstein (2003), necessária para que o direito à saúde seja prática social inerente à condição humana concretizada no cotidiano da vida das pessoas. Para todos os entrevistados, esse direito está ligado à condição de cidadão:

$\varepsilon$ o direito que eu tenho como cidadã de ser atendida [...] com um atendimento digno, com qualidade. Porque a pessoa, provavelmente, quando procura um atendimento, ela tá debilitada, né? (GF3)

O direito à saúde está intimamente ligado a uma condição de cidadania ativa, ou seja, "uma constante luta contra qualquer constrangimento que impeça o seu exercício" (Nogueira e Pires, 2004, p. 755), e não pode ser resumido à formalização em leis sem a sua concretização no cotidiano das pessoas. Para os autores é necessário considerar o direito à saúde no plano político como uma instância de luta coletiva para que sejam deslocados do plano meramente formal e não histórico. Segundo Dallari (1988), a efetividade desse direito se dará de acordo com o grau de desenvolvimento socioeconômico e cultural do Estado e conforme a participação dos indivíduos no processo.

\section{A universalidade do direito à saúde: formal ou real?}

A efetividade do direito, como estabelecido no ordenamento jurídico brasileiro, é questionada pelos sujeitos desta pesquisa: A constituição fala também que saúde é um direito de todos, né? Só que na prática esse direito é restrito, né? Muito restrito [...] (GF3). Eles separam o direito à saúde enquanto norma, expressa em leis, do direito enquanto fenômeno real. 
Quando se referem ao direito à saúde como universal referem-se ao que a norma determina; entretanto apontam que sua efetividade e seu usufruto não são para todas as pessoas. Há um paradoxo apresentado entre a norma e a realidade.

Pachukanis (1988) atenta-nos a perceber que a distância entre "Dever Ser" e "Ser" cria uma barreira intransponível para compreensão e a efetivação do direito, uma postura de manutenção do status quo. Para ele, o direito que se encerra em uma hierarquia de normas, dentro dos limites da categoria eterna do "Dever Ser", sem contato com o fenômeno, o "Ser", nada mais é do que a máscara que encobre as lutas de classe e as relações de poder. Como argumenta Merhy (2012), não é de hoje que no Brasil algumas vidas valem mais que outras e algumas pessoas possuem mais direitos que outras. Segundo esse autor, desde a Constituição de 1988 houve uma reversão da aposta inicial do Sistema Único de Saúde, tanto no sentido organizacional quanto no sentido diretivo, regulatório, avaliativo, financeiro e do próprio processo de cuidado em saúde. Para Merhy, o SUS exerce função suplementar ao setor privado, quando deveria ser o contrário. Assim também descrevem os entrevistados desta pesquisa.

Poucas oportunidades, às vezes a gente vê pelo Sistema Único de Saúde. O atendimento, como é demorado, 'é' poucas vagas pra muita gente (GF3)

De um modo geral, todos apontam o descaso do Estado com a política de saúde pública por responder a interesses não prioritários da sociedade, sendo, antes, interesses particulares que deslocam a estruturação dos serviços públicos de saúde para segundo plano:

Eles 'tá' preocupado é com a Copa do Mundo no Brasil, é com o campo, não quer saber de saúde, não. Quantos bilhões eles tão dando pro futebol? Não tão preocupando nem com um milhão pra saúde (GF1)

O Estado para Marx e Engels é produto da contradição da sociedade dividida por antagonismos irreconciliáveis entre as classes econômicas, em função das relações de produção, para a qual se faz necessário um poder aparentemente acima e distante dela. Há uma suposta separação entre o interesse público, salvaguardado pelo Estado, do interesse privado próprio da sociedade civil capitalista. Mas, como o Estado nasce do conflito de interesses das classes, é o interesse da classe economicamente dominante que ele representa, ao mesmo tempo em que é por intermédio dele que essa classe converte-se em politicamente dominante, utilizando dos meios repressivos para exploração da classe oprimida (Mascaro, 2002). 0 interesse privado se sobrepõe ao interesse público, mas de forma mascarada, pelo direito que se pretende universal: "os direitos concedidos aos cidadãos são regulados de acordo com as posses dos referidos cidadãos, pelo que se evidencia ser o Estado um organismo para proteção dos que possuem contra os que não possuem" (Engels, 1982, p. 137).

A promulgação do direito à saúde no Brasil, fruto de movimentos sociais envolvidos no processo de redemocratização do país e produtores da Reforma Sanitária Brasileira, ocorreu, como explica Campos (2008), concomitantemente ao neoliberalismo, que favoreceu o mercado e o afastamento do Estado dos setores sociais. Para Fleury (2009), nos últimos anos, há um retrocesso na construção de saúde como um valor público: sob orientação neoliberal, a saúde passa a ser um bem de consumo, individualizado, com anuência e promoção do Estado. A classe burguesa avança com incentivos fiscais, transferência de serviços e prestações para o setor privado, corte de gastos públicos nas políticas sociais e consequente atrofia do papel do Estado em efetivar os direitos sociais. O que se vê com o capitalismo avançado é a retirada dos direitos conquistados pelos movimentos de lutas populares, tornando o acesso aos serviços de saúde passível de ser negociado e comprado, limitado a quem possui mais condições financeiras. Para tornar-se cidadão é necessária a integração do individuo ao mercado, como consumidor e como produtor (Queiroz, 2006). Essa análise se harmoniza com a fala dos entrevistados:

Hoje em dia, se você tiver dinheiro você tem isso tudo e mais ainda. Agora, se você não tem dinheiro, você não tem nada. Saneamento básico, principalmente, comida, saúde, não tem nada (GF2).

Há uma compreensão, para os sujeitos desta pesquisa, de que a efetivação do direito à saúde na vida das pessoas é intimamente ligada ao aspecto econômico. E essa situação contraditória, de um lado, o direito universal institucionalizado, 
de outro, sua negação à população de menor nível socioeconômico, reedita a análise de Marx, para quem a afirmação do direito como universal esconde as diferenças entre explorados e exploradores, a luta de classes presente no capitalismo e, por fim, determina o império da lógica burguesa. 0 direito jusnatural evolui pela necessidade de se assegurar o funcionamento do sistema por meio de instâncias estabelecidas pelas relações produtivas, configurando o direito como de classe e no interesse da classe exploradora. Sendo assim, o direito universal e igual é formalizado apenas em lei e não em sua concretude, uma vez que no capitalismo o trabalhador e o capitalista, apesar de estarem em conflito, perante o direito são tratados da mesma forma, escondendo as desigualdades materiais (Mascaro, 2002).

\section{E como é para as pessoas em privação de liberdade?}

Do mesmo modo que o direito à saúde de todos, o direito à saúde das pessoas em privação de liberdade é percebido por elas próprias enquanto norma que não se concretiza no cotidiano da vida:

Direito a saúde não é deixar a gente aqui, entendeu? o preso aqui tem que procurar saber como que 'tá' a saúde dele, do que ele 'tá' precisando, se não tem gastrite ou ulcera ou aids ou câncer ou um problema de pele. [...] Às vezes a família dele vai lá, marca um médico, entendeu? Às vezes não tem escolta, às vezes alguma coisa que precisava, algum procedimento não dá pra levar o preso e nisso vai ficando. E a saúde, como é que fica? Entendeu? É que eu gostaria, se teria disponibilidade, que o governo se preocupasse mais 'da'nossa saúde. [...] Eu não tenho ninguém pra me ajudar, então eu vou fazer o quê? (GF1).

Essa percepção é compartilhada tanto pelos profissionais de saúde quanto pelos agentes penitenciários que relatam a precariedade dos serviços de saúde dentro da unidade prisional estudada e a falta de atenção aos detentos:

Eles não têm direito a nada aqui, ninguém dá atenção a eles aqui. Eles estão jogados (GF3).

Praticamente não existe. A dentista vem pra bater ponto. Assim, que o aparelho tá quebrado já tem muito tempo. Então não tem. Tem o direito, mas não tem acesso. Eles vão lá, balangam², balangam. A gente vai, escuta isso todo dia. E fala e fala, e não resolve outra coisa (GF2).

Estudos publicados sobre a saúde das pessoas privadas de liberdade (Menezes, 2002; Sequeira, 2006; Coelho, 2009), bem como os relatórios de entidades ligadas aos direitos humanos (Brasil, 2010b; Mesquita Neto e Alves, 2007; CEJIL, 2007), demonstram que as condições insalubres do cárcere - o confinamento, a superlotação, as precárias condições de higiene, a falta de estrutura adequada e suficiente para o atendimento médico, alimentos de má qualidade e aquém do necessário, ausência de uma política substancial de inserção em atividades laborais, a violência e o abalo emocional - são fatores que aumentam e propiciam infecções. De acordo com Menezes (2002), no Brasil pelo menos 20\% da população presa é infectada pelo vírus da aids e da hepatite $\mathrm{B}, 10 \%$ pelo bacilo da sífilis e vírus da hepatite C. Segundo Pedroso (1997), essa é uma situação que marca a história do sistema penitenciário brasileiro e que revela o descaso das políticas públicas em matéria penal.

Esse descaso, na avaliação dos entrevistados, é justificado pelas funções da prisão, segurança e disciplina:

Primeiro a gente trabalha com segurança. Entre o preso morrer dentro da cela e eu arriscar abrir uma brecha pra ter rebelião dentro do presídio, um pavilhão, infelizmente ele vai morrer dentro da cela. Entendeu?(GF2).

[...] é aquele negócio... direito preso? Preso tem que ter direito a alguma coisa? Preso tem que ter disciplina!' (GF3).

Para Foucault (1986) a disciplina como tática de poder se enraizou com o início do sistema de produção capitalista. A sociedade burguesa abriga-se num sistema de direitos formalmente universais e igualitários, sustentado por esses mecanismos de micropoder que constituem as disciplinas, que se apresenta como uma espécie de "contradireito" (Foucault, 1986). A disciplina insere uma relação de subordinação de um indivíduo sobre o outro,

\footnotetext{
2 A expressão "balangam" se refere à prática adotada pelos detentos de bater na porta da cela quando se faz necessária uma assistência à saúde de urgência.
} 
concentrando "mais-poder" (Foucault, 1986) sempre do mesmo lado, afirmando a desigualdade de posição entre os indivíduos em relação ao regulamento comum, enquanto que os sistemas jurídicos qualificam os sujeitos de direito de acordo com as normas universais.

A pena de prisão assume um caráter de aparelho disciplinar exaustivo em todos os aspectos do indivíduo: treinamento físico do indivíduo, aptidão ao trabalho, comportamento, atitude moral, disposições individuais (Foucault, 1986). Como dizem os agentes: $O$ sistema, ele é todo manipulado exatamente pra ficarnum controle autoritário, totalmente assim, né? (GF2). Assim, a prisão vai além da privação da liberdade como punição do delito e passa a ter a função de modular a pena, quantificar e graduar o castigo, segundo a obediência às ordens hierárquica do aprisionado (Foucault, 1986).

Ele sabe que ele errou, que tem que ser feito daquela forma, tem que aplicar aquela punição, quase sempre é comunicação, ou COC (Centro de Observação Criminológica) mesmo, fica lá isolado e tudo. Mas a maioria dos problemas nossos não são diretamente ligados a eles, porque aqui a gente dá ordem, tem que cumprir, se ele não cumprir por bem vai cumprir por mal. Mal pra ele, pra gente nem tanto. Mas se precisar a força vai ter que ser usada a força, fazer o quêe? (GF2).

O direito à saúde pode ser empregado, quando da reivindicação, como um direito individual privilegiando a liberdade para escolher o tipo de relação que a pessoa terá com o território, o tipo de vida que quer viver, o tipo de tratamento a que será submetida (Dallari, 1988). Mas, como apontam Diuana e colaboradores (2008), aos presos é negada a condição de paciente, uma vez que estão submetidos à ordem: para ter acesso aos serviços de saúde é preciso que os detentos se submetam aos valores hierárquicos e às relações de dívida e gratidão.

$\varepsilon$ hoje até teve um preso que eu tava atendendo agora e eu achei interessante. Eu perguntei a ele se tinha aqui procedimento que eu posso ajudar. $E$ ele: 'Não, doutora, é só isso mesmo e tal. Toda vez que eu preciso 'vim' aqui no núcleo eles me trazem, eu sempre sou atendido. $O$ meu tratamento tá sendo muito bem feito, eu sou hipertenso, tô recebendo toda a minha medicação e tal'. Aí eu falei assim: 'e como é que é? Você?' Ai, assim, ele falou: 'eu nunca fui pro COC, eu não tenho problema nenhum com os agentes'. Então, assim, se você consegue ter bom relacionamento eu acho que é mais fácil de você conseguir que o seu direito seja respeitado (GF3).

O acesso aos serviços de saúde também pode ocorrer por meio do pagamento pelos serviços de saúde extramuros: eu conversei com assistente social e ela 'falô' que só se a família tivesse dinheiro lá fora pra pagá lá fora, pra 'levá'(GF1). O que, segundo as normas jurídicas, o Estado deveria prover, no caso das pessoas em privação de liberdade passa a ser responsabilidade da família, seja por ela ter condições financeiras para pagar, seja ela usuária que procura e pressiona os serviços públicos de saúde, extramuros e intramuros, aos quais os presos terão acesso.

Na maioria das vezes só tira 'nóis' pra atendimento, na maioria das vezes com a família (GF1).

Uma coisa eu já falo: 'não prometo nada'. Eu chego falo isso: 'vou tentar resolver'. Porque eu chego aqui em cima, às vezes eu preciso de autorização de coordenador, de um diretor. Aí, beleza, eu consigo aqui, mas não consigo lá fora, ai a gente liga pra família... (GF3).

A presença da família durante a execução penal e a importancia de seu papel na sobrevivência dos presos, para garantia do acesso a serviços - jurídicos e de saúde - e denúncia de abusos e punições ilegais foram demonstradas por Guimaraes e colaboradores (2006), em estudo realizado na cidade de Porto Alegre. A família a que se refere é predominantemente composta por mulheres, de baixa condição socioeconômica, estigmatizadas pelos gestores da prisão que as responsabilizam pela criminalidade. Nós também encontramos as profissionais de saúde, mulheres, pejorativamente sendo chamadas de mães de preso por tentarem fazer valer o direito do preso (GF3).

Se por um lado, é consensual entre os entrevistados, a crítica de não efetivação do princípio de universalidade do SUS, por outro lado, porém - e de forma contraditória -- há certa recusa em atribuir este direito ao preso. A percepção de profissionais e de agentes penitenciários é de que o acesso aos serviços de saúde, mesmo que precários, proporcio- 
na uma condição de vantagem aos detentos, de ter mais direito que os demais sujeitos envolvidos no contexto do sistema penitenciário:

Mas se você for pensar, né? Mesmo assim eu acho que ainda no.. no sistema prisional ainda tem mais direito que quem tá lá fora (GF3).

Mas o direito mesmo quem tem é o preso. Igual ele tem direito a advogado, a escola, essas 'coisa toda'. Então, quem tem direito mesmo é o preso (GF2).

O entendimento por profissionais de saúde e agentes penitenciários do acesso aos serviços de saúde como vantagem dada ao preso tem relação com a insatisfação com as precárias condições de trabalho a que estão submetidos, compreendidas como ausência de direito, provocando, por consequência, uma atitude de negação desse suposto mais direito do outro:

Éruim, porque vai falar de profissional, de colegas de serviço, né? Mas às vezes se a colega não tiver bem pra trabalhar, ela esbarra nisso. Nega o direito que o outro tem porque eu não tô tendo (GF3).

É porque, querendo ou não, eles 'é' albergado, eles vêm todo dia na cadeia. Então, querendo ou não, eles pagam cadeia também, e é trabalhar definitivo. [...] o salário ébaixo, né? Corre risco de vida desde os familiares deles. Mil e oitocentos reais, isso é dinheiro pra ter uma responsabilidade grande dessa? (GF1).

As condições de trabalho - vínculos precarizados, baixos salários, falta de atendimento à saúde física e mental, violência institucional - a que estão submetidos tanto os profissionais de saúde quanto os agentes penitenciários da unidade prisional pesquisada, foram objetos de estudo em outros Estados. Essas pesquisas indicam existir relação forte entre tais condições e o comprometimento da saúde física e mental dos trabalhadores, bem como com o comportamento agressivo em relação às pessoas presas (Fernandes e col., 2002; Diuana e col., 2008).

Há, muitas vezes, na recusa ao direito à saúde do preso um julgamento moral: criminoso (GF3). Se o crime é algo que traz dano moral à sociedade, o criminoso passa a ser o "inimigo social”" (Foucault,
2003); aquele que rompeu com um pacto que, em tese, havia estabelecido e, portanto, não pode ser tratado da mesma maneira que outras pessoas cujos comportamentos não ferem o moralmente concebido como conduta correta:

65 anos. Sabe aquele homem assim conservador, de valores conservados, preservados? Ele tá aqui no fim do mundo, mas ele tava com cabeça baixa, humilde, nem gostava muito de falar. Graças ao Senhor ele já saiu, né? Justiça foi feita! Mas, ai, eu vou tratar esse senhor de 65 anos igual ao que, desde 11 anos, como eu atendi semana passada: 'eu roubo desde 11 anos, então nunca gostei de trabalharnão, doutora, eu roubo desde os 11'. Não, não posso tratar da mesma maneira (GF3).

O julgamento moral como um elemento discriminador que dificulta o acesso aos serviços de saúde é confirmado e denunciado pelos presos. Entretanto, a recusa ao direito é reproduzida por eles quando se referem aos detentos que estão no "seguro" - pavilhão segregado para pessoas que cumprem pena de prisão por estupro, não pagamento de pensão alimentícia, entre outros, e os presos que delatam outros à direção do presídio. A expressão mais direito é também utilizada por detentos quando se remetem à concretização do direito à saúde para os presos do seguro. Há um julgamento moral de que crimes como os descritos acima são típicos de pessoas sem caráter (GF1), e que a punição a eles deveria ser mais severa, sugerindo pena de morte, execução: A lei tinha que ser mais severa, tanto no crime de estupro quanto nos duzentão (GF1).

0 direito à saúde em seus aspectos sociais privilegia a igualdade, sendo as limitações aos comportamentos humanos estabelecidas para que todos usufruam igualmente das vantagens da vida em sociedade e dos cuidados em saúde (Dallari, 1988). A igualdade formal, assim como a universalidade, para Pachukanis (1988) é, além de uma dissimulação da exploração capitalista, um princípio realmente atuante e incorporado pela sociedade burguesa como um princípio moral e de transformação das relações humanas em relações jurídicas. Consequentemente,

30 termo "duzentão" é utilizado quando se deseja fazer referência aos crimes inseridos no Título VI - dos crimes contra a dignidade sexual - do Código Penal Brasileiro, Decreto-Lei n².848, de 7 de dezembro de 1940. 
se se reconhecer o outro como igual é imprescindível para o reconhecimento do direito, o julgamento moral sobre o comportamento de uma pessoa que quebra o pacto social a discrimina e impede o reconhecimento de que o direito à saúde seja efetivado de maneira igual. A quem possui uma conduta que fere o que é moralmente correto deve-se destinar menor atenção, menor acesso aos serviços de saúde, provocando o que chamamos de dupla penalização. Ela é entendida como o conjunto do isolamento da pena de prisão, oriunda do julgamento jurídico próprio do processo penal, e da constante violação de direitos a que uma pessoa em privação de liberdade é submetida, procedente do julgamento moral sob o comportamento do preso durante a execução da pena.

\section{Considerações finais}

A saúde para os sujeitos desta pesquisa - pessoas presas, agentes penitenciários e profissionais de saúde - não se limita à ausência de doenças, físicas ou mentais, sendo o processo saúde-doença determinado por outras condições de vida como liberdade, família, respeito ao próximo, trabalho. Para eles, saúde é um direito cuja efetividade dar-se-ia pela garantia do acesso integral e com qualidade aos serviços de saúde, e está restrito à parcela da população que pode pagar por tais serviços. Dessa forma, o direito universal à saúde é questionado enquanto fenômeno real, apesar de ser garantido enquanto norma jurídica.

A pesquisa revela o descaso do Estado com os detentos, submetendo-os a condições desumanas e insalubres, o que aumenta a sua vulnerabilidade às doenças. As relações estabelecidas são de violência nas quais indivíduos vulneráveis - como o são as pessoas presas - veem-se constrangidos às posições de submissão a uma ordem disciplinar hierárquica para ter acesso aos serviços de saúde. Além disso, há um constante julgamento moral sobre o comportamento do preso, quando da operacionalização de seu acesso às ações de saúde, culminando muitas vezes na não efetivação desse acesso. As precárias condições de trabalho apontam também para a não realização dos direitos dos trabalhadores inseridos no contexto carcerário - profissionais de saúde e os agentes penitenciários -, o que acarreta, muitas vezes, ressentimentos e recusa em atribuir o direito à saúde à pessoa presa.

O campo de produção de conhecimento e do cuidado em saúde, desde o início da Reforma Sanitária até os dias de hoje, postula sujeitos de vontade, desejos e conhecimentos produtores de modos de vida, de significados e sentidos (Merhy, 2012), protagonistas da construção tanto de práticas de saúde no dia a dia de suas vidas, quanto de serviços e ações de saúde que possibilitem alcançar um patamar de produção e reprodução da vida (Reis e col., 2004) que lhes seja satisfatória. Ou seja, a partir da luta pela Reforma Sanitária, a saúde foi compreendida como uma prática de libertação das relações de opressão e de constante construção da cidadania (Reis, e col., 2004; Carvalho, 2009).

Em uma situação de encarceramento, que objetifica as pessoas e as coloca em relações de opressão hierarquizadas, desumanas e embrutecedoras, aprisiona-se também a dimensão da saúde construída pela Reforma Sanitária Brasileira. É preciso atentar-nos para o fato de que a lógica de encarceramento está, quase sempre, destinada a um mesmo público: jovens, pobres, afrodescendentes, envolvidos em atos de viés econômico, que historicamente vivem um processo de marginalização e exclusão social (Lopes e col., 2008). Reforça esta percepção o perfil da população brasileira presa: $55 \%$ dos membros são jovens de 18 a 29 anos, $46 \%$ têm até o ensino fundamental completo, $60 \%$ são afrodescendentes, $38 \%$ foram presos por crimes contra o patrimônio e $19 \%$ por envolvimento com entorpecentes, segundo os dados do Departamento Penitenciário Nacional (Brasil, 2012).

Enquanto o direito universal à saúde como prática de democratização do Estado, da saúde, da sociedade e da cultura (Paim, 2008) não se concretiza para as pessoas em privação de liberdade, a pena de prisão é um fenômeno real que materializa o contradireito (Foucault, 1986), contraditoriamente sustentado pelo direito penal. Ainda que leis nacionais postulem que a pena de prisão apenas pode privar a pessoa de sua liberdade, não de outros direitos, como o da saúde, e que é dever do Estado prover tais direitos, admitindo também uma possibilidade de caráter reformatório da prisão, o que se vê 
na materialidade é que a pena de prisão assume um caráter cruel, violento e de reprodução da violência institucional contra as pessoas presas e contra os profissionais ali inseridos.

A partir desta pesquisa, concluímos que a efetivação do direito à saúde das pessoas em privação de liberdade vai além da garantia de acesso às ações e aos serviços públicos e estatais de saúde. A efetivação desse direito requer o rompimento com a lógica punitiva de encarceramento da sociedade disciplinar, assim como o fez a luta antimanicomial. Esse rompimento pressupõe, como vêm discutindo os criminologistas, o deslocamento de eixo tanto do espaço quanto do modelo de solução dos conflitos, do Estado para comunidade, promovendo laços de solidariedade e o controle local (Zaffaroni, 1991). Alinhar a construção da política do cuidado em saúde das pessoas em privação de liberdade a essa nova perspectiva é estritamente necessário para a construção de um direito à saúde que vá além da formalidade e de um sistema único de saúde que seja concretamente universal, integral, equitativo e capaz de envolver o conjunto de sujeitos participantes do processo de produção da saúde.

\section{Contribuição dos autores}

Martins, E. foi responsável pela concepção e realização do projeto, análise e interpretação dos dados, redação do artigo e revisão crítica relevante do conteúdo intelectual. Martins, L. foi responsável pela realização do projeto. Silveira fez a revisão crítica relevante do conteúdo intelectual. Melo foi responsável pela concepção do projeto e revisão crítica relevante do conteúdo intelectual.

\section{Referências}

ASSIS, R. D. A realidade atual do sistema penitenciário brasileiro. Revista CEJ, Brasília, DF, v. 11, n. 39, p. 74-78, 2007.

BODSTEIN, R. C. Democracia e cidadania: notas para um debate sobre o direito à saúde. Ciências \& Saúde Coletiva, Rio de Janeiro, v. 8, n. 1, p. 19-32, 2003.
BORGES NETTO, A. L.; SILVA, A. S. Os policiais civis e a custódia de presos. Jus Navigandi, Teresina, v. 12, n. 1469, jul. 2007. Disponível em: <http://jus.com.br/artigos/10134>. Acesso em: 6 jun. 2014.

BRASIL. Ministério da Justiça. Lei n ${ }^{0}$ 7.210, de 11 de julho de 1984. Institui a Lei de Execução Penal. Diário Oficial da União, Brasília, DF, 13 jul. 1984. Seção 1, p. 10227.

BRASIL. Constituição da República Federativa do Brasil de 1988. Diário Oficial da União, Brasília, DF, 5 out. 1988. Disponível em: <http:// www.planalto.gov.br/ccivil_o3/constituicao/ constituicao.htm>. Acesso em: 7 out. 2013.

BRASIL. Câmara dos Deputados. Relatório da II Caravana Nacional Direitos Humanos: uma amostra da realidade prisional brasileira. Brasília, DF, 200o. Disponível em: <http://www.dhnet.org. $\mathrm{br} /$ dados/caravanas/br/iicaravana.html>. Acesso em: 7 out. 2013 .

BRASIL. Ministério da Saúde. Ministério da Justiça. Portaria Interministerial $n^{0} 1.777$, de 9 de setembro de 2003. Institui o Plano Nacional Saúde no Sistema Penitenciário. Diário Oficial da União, Brasília, DF, 11 set. 2003. Seção 1, p. 39-43.

BRASIL. Ministério da Saúde. Secretaria de Atenção à Saúde. Departamento de Ações Programáticas Estratégicas. Legislação em saúde no sistema penitenciário. Brasília, DF, 2010.

BRASIL. Ministério da Justiça. Departamento Penitenciário Nacional. Relatório estatístico/ analíticos do Sistema Nacional de Informação Penitenciária - Infopen. Brasília, DF, 2012. Disponível em: <http://portal.mj.gov.br/main. asp?View=\% $7 \mathrm{BD}_{574} \mathrm{E}_{9} \mathrm{CE}-3 \mathrm{C} 7 \mathrm{D}-437 \mathrm{~A}-\mathrm{A}_{5} \mathrm{~B} 6$ 22166AD2E896\%7D\&Team $=$ \&params $=$ itemID $=\% 7$ BD82B764A-E854-4DC2-Ao18-45oDoD10o9C7\% 7D;\&UIPartUID =\%7B2868BA3C-1C72-4347-BE11$\mathrm{A}_{26} 6 \mathrm{~F}_{70} \mathrm{~F}_{4} \mathrm{CB}_{2} 6 \% 7 \mathrm{D}>$. Acesso em: 5 jun. 2014.

BUSS, P. M. Promoção da saúde e qualidade de vida. Ciênciađ Saúde Coletiva, Rio de Janeiro, v. 5 , n. 1, p. 163-177, 2000. 
CAMPOS, G. W. S. SUS depois de vinte anos:

reflexões sobre o direito à atenção à saúde.

Boletim do Instituto de Saúde, São Paulo, p. 36-38, out. 2008. Número especial.

CARVALHO, S. R. Reflexões sobre o tema cidadania e a produção de subjetividade no SUS. In: CARVALHO, S. R.; BARROS, M. E.; FERRIGATO, S. (Org.). Conexões: saúde coletiva e políticas de subjetividade. São Paulo: Hucitec, 2009. p. 23-41.

CEJIL - CENTRO PELA JUSTIÇA E PELO DIREITO INTERNACIONAL. Relatório sobre as mulheres encarceradas no Brasil. Natal, 2007. Disponível em: <http://asbrad.com.br/conte\%C3\%BAdo/ relat\%C3\%B3rio_oea.pdf>. Acesso em: 7 out. 2013.

COELHO, H. C. et al. Soroprevalência da infecção pelo vírus da hepatite B em uma prisão brasileira. Revista Brasileira de Epidemiologia, São Paulo, v. 12, n. 2, p. 124-131, 2009.

CONSELHO NACIONAL DE JUSTIÇA. Mutirão carcerário do Estado de Minas Gerais: relatório geral, 2010. Belo Horizonte, 2010. Disponível em: <http://www.cnj.jus.br/images/programas/ mutirao-carcerario/relatorios/minasgerais.pdf $>$. Acesso em: 15 maio 2014 .

DALLARI, S. G. O direito à saúde. Revista de Saúde Pública, São Paulo, v. 22, n. 1, p. 57-63, 1988.

DIUANA, V. et al. Saúde em prisões:

representações e práticas dos agentes de segurança penitenciária no Rio de Janeiro, Brasil. Cadernos de Saúde Pública, Rio de Janeiro, v. 24, n. 8, p. 1887-1896, 2008.

FERNANDES, R. C. P. et al. Trabalho e cárcere: um estudo com os agentes penitenciários da Região Metropolitana de Salvador, Brasil. Cadernos de Saúde Pública, Rio de Janeiro, v. 18, n. 3, p. 807816, 2002.

FLEURY, S. Reforma sanitária brasileira: dilemas entre o instituinte e o instituído. Ciência \& Saúde Coletiva, Rio de Janeiro, v. 14, n. 3, p. 743-752, 2009.

FOUCAULT, M. A verdade e as formas jurídicas. Rio de Janeiro: Nau, 2003.

FOUCAULT, M. Vigiar e punir: nascimento da prisão. 4. ed. Petrópolis: Vozes, 1986.
GASKELL, G. Entrevistas individuais e grupais. In: BAUER, M. W.; GASKELL, G. (Ed.). Pesquisa qualitativa com texto, imagem e som. 7. ed. Petrópolis: Vozes, 2008. p. 64-89.

GATTI, B. A. Grupo focal na pesquisa em ciências sociais e humanas. Brasília, DF: Liber Livro, 2005.

GILL, R. Análise de discurso. In: BAUER, M. W.; GASKELL, G. (Ed.). Pesquisa qualitativa com texto, imagem e som. 7. ed. Petrópolis: Vozes, 2008. p. 244-270.

GUIMARÃES, C. F. et al. Homens apenados mulheres presas: estudos sobre mulheres de presos. Psicologia \& Sociedade, Porto Alegre, v. 18, n. 3, p. 48-54, 2006.

LOPES, R. E. et al. Juventude pobre, violência e cidadania. Saúde e Sociedade, São Paulo, v. 17, n. 3, p. 63-76, 2008.

ENGELS, F. A origem da família, da propriedade privada e do Estado. In: MARX, K.; ENGELS, F. Obras escolhidas. São Paulo: Alfa-Omega, 1982. v. 3. p. 7-143.

MASCARO, A. L. Introdução à filosofia do direito: dos modernos aos contemporâneos. São Paulo: Atlas, 2002.

MATTOS, R. A. Os sentidos da integralidade: algumas reflexões acerca de valores que merecem ser defendidos. In: MATTOS. R. A. (Org.). Os sentidos da integralidade na atenção e no cuidado à saúde. Rio de Janeiro: UERJ, IMS, 2006. p. 48-54.

MENEZES, R. P. O. Projeto de implantação do controle da tuberculose nas instituições penais do Município de Salvador/BA. Boletim de Pneumologia Sanitária, Rio de Janeiro, v. 10, n. 2, p. 35-40, 2002.

MERHY, E. Saúde e direitos: tensões de um SUS em disputa e molecularidades. Saúde e Sociedade, São Paulo, v. 21, n. 2, p. 267-279, 2012.

MESQUITA NETO, P.; ALVES, R. Relatório nacional sobre os direitos humanos no Brasil. São Paulo: Universidade de São Paulo, Núcleo de Estudos da Violência, 2007. Disponível em: <http://www. nevusp.org/downloads/downog9.pdf >. Acesso em: 15 maio 2014. 
MINAYO, M. C. S. O desafio do conhecimento: pesquisa qualitativa. 12. ed. São Paulo: Hucitec, 2010 .

NOGUEIRA, V. M. R.; PIRES, D. E. P. Direito à saúde: um convite à reflexão. Cadernos de Saúde Pública, Rio de Janeiro, v. 2o, n. 3, p. 753-76o, 2004.

PACHUKANIS, E. Teoria geral do direito e marxismo. São Paulo: Acadêmica, 1988.

PAIM, J. S. Reforma sanitária brasileira: contribuição para a compreensão e crítica. Salvador: Edufba; Rio de Janeiro: Fiocruz, 2008.

PEDROSO, R. C. Utopias penitenciárias projetos jurídicos e realidade carcerária no Brasil. Revista de História, São Paulo, v. 136, p. 121-137, jan./jun. 1997.

PINHEIRO, R. et al. Demanda em saúde e direito à saúde: liberdade ou necessidade?: algumas considerações sobre os nexos constituintes das práticas de integralidade. In: PINHEIRO, R.; MATTOS, R. A. (Org.). Construção social da demanda: direito à saúde, trabalho em equipe, participação e espaços públicos. Rio de Janeiro: UERJ, Cepesc: Abrasco, 2010.
QUEIROZ, R. Direitos humanos e saúde. Saúde e Direitos Humanos, Brasília, DF, v. 3, n. 3. p. 45-5o, 2006.

REIS, A. O. A. et al. A humanização da saúde como instância libertadora. Saúde e Sociedade, São Paulo, v. 13, n. 3, p. 36-43, 2004.

SEQUEIRA, V. C. Uma vida não vale nada: prisão e abandono político-social. Psicologia Ciência e Profissão, Brasília, DF, v. 26, n. 4, p. 66o-671, 2006.

WALMSLEY, R. World prison population list. $8^{\text {th }}$. ed. London: King's College London, International Center for Prison Studies, 2009. Disponível em: <http://www.apcca.org/uploads/8th_Edition_20o9. pdf $>$. Acesso em: 15 maio 2014.

WESTPHAL, M. F. et al. Grupos focais: experiências precursoras em programas educativos em saúde no Brasil. Boletín de la Oficina Sanitaria Panamericana, Washington, DC, v. 120, n. 6o, p. 472-482, 1996.

ZAFFARONI, R. E. Em busca das penas perdidas: a perda da legitimidade do sistema penal. Rio de Janeiro: Revan, 1991. 